\title{
La influencia de la experiencia jurídica italiana en el Código Civil peruano en materia de responsabilidad civil
}

\author{
Juan Espinoza Espinoza
}

\section{Introducción}

A no dudarlo, en materia de responsabilidad civil extracontractual, el Código Civil peruano tiene diversos puntos de contacto con el Código Civil italiano. En efecto, estos puntos de contacto los encontramos desde la cláusula general de la responsabilidad civil, en la cual se establece que quien ocasiona un daño al otro está obligado a indemnizarlo (arts. 2043。 del c.c. ita. y $1969^{\circ}$ del c.c.p.), pasando por las causas de justificación, como la legítima defensa (Art. $2044^{\circ}$ del c.c.ita. y $1971^{\circ} .2$ del c.c.p.), el estado de necesidad (Art. $2045^{\circ}$ del c.c.ita. y $1971^{\circ} .3$ del c.c.p.) o la situación de irresponsabilidad por pérdida de conciencia (Art. $2046^{\circ} \mathrm{del}$ c.c.ita. y $1974^{\circ}$ del c.c.p.). En materia de obligación a resarcir, ambos textos establecen que el representante del denominado incapaz (privado de discernimiento) responde por los daños ocasionados por este, salvo que dicho representante no pueda solventar los mismos, en cuyo caso se aplica una indemnización equitativa, a cargo del denominado incapaz (arts. $2047^{\circ}$ del c.c.ita. y $1976^{\circ}$ y $1977^{\circ}$ del c.c.p.). La responsabilidad de los padres por los actos de los hijos (arts. $2048^{\circ}$ del c.c.ita. y $458^{\circ}$ del c.c.p.), la del principal con respecto de los actos de los dependientes (arts. 2049 ${ }^{\circ}$ del c.c.ita. y $1981^{\circ}$ del c.c.p.), la responsabilidad por el ejercicio de las actividades peligrosas (arts. $2050^{\circ}$ del c.c.ita. y $1970^{\circ}$ del c.c.p.), la responsabilidad del dueño por los daños que ocasionan sus animales (arts. $2052^{\circ}$ del c.c.ita. y $1979^{\circ}$ del c.c.p.), o por la ruina de su edificio (arts. $2053^{\circ}$ del c.c.ita. y $1980^{\circ}$ del c.c.p.) y la responsabilidad solidaria (arts. $2055^{\circ}$ del c.c.ita. y $1983^{\circ}$ del c.c. p.), también son supuestos de hecho comunes en ambos textos legislativos. 
Se podrá tener diferencias de terminología (como en el caso que el Código Civil italiano habla del «daño injusto», mientras que el peruano del daño tout court, o que el Código Civil italiano se refiere al uincapaz de querer y entender", mientras que el peruano hace lo propio con el "privado de discernimiento»; pero, en la mayoría de los casos existe un bumus común. No obstante ello, ambos modelos legislativos han sido interpretados (tanto a nivel doctrinario como jurisprudencial) de diversa manera. El objetivo de este trabajo es el de comparar experiencias entre el sexagenario Codice y el apenas "mayor de edad" código civil peruano en lo que a responsabilidad civil extracontractual se refiere y abrir nuevos horizontes interpretativos.

\section{Análisis de los antecedentes legislativos}

Para iniciar un estudio comparativo entre el Código Civil italiano y el peruano en materia de responsabilidad civil, es necesario remontarse al Código Civil peruano de 1936, así como el proyecto franco-italiano del código de obligaciones y contratos de 1927. En efecto, si bien es cierto que el Código Civil peruano de 1984 ha asimilado directamente figuras del Código Civil italiano de 1942, como es el caso de la, ya referida, responsabilidad por el ejercicio de las actividades peligrosas, o el de la responsabilidad civil de los profesionales (arts. $2236^{\circ}$ c.c. ita. y $1762^{\circ}$ c.c.p), este también ha seguido la línea ya trazada por su predecesor, el Código Civil de 1936, el cual —al igual que el Código Civil italiano de 1942 - al menos en esta materia, ha tenido una fuerte influencia del proyecto franco-italiano. ${ }^{1}$

Este itinerario comenzará con el análisis de la imputabilidad: en efecto, el modelo jurídico circulante de la capacidad para hacerse responsable por los actos ilícitos cometidos con discernimiento, regulada en los arts. $458^{\circ}$ y $1975^{\circ}$ c.c., se remonta a los arts. $515^{\circ 2}$ y $1139^{\circ 3}$ del Código Civil

\footnotetext{
1 Este proyecto fue elaborado por juristas de la talla de Ascoli, De Ruggiero, Capitant, Colin y Ripert.

2 El cual establecía que «el menor capaz de discernimiento responde del daño causado por sus actos ilícitos".

3 Que precisaba que «el incapaz queda obligado por sus actos ilícitos siempre que hubiese procedido con discernimiento".
} 
de 1936 , los cuales, a su vez, se han inspirado en el Art. $75^{\circ 4}$ del proyecto franco-italiano de 1927. Como ya se indicó, el Código Civil italiano de 1942 prefiere referirse a la "capacidad de entender y querer".

La responsabilidad objetiva de los representantes de los incapaces, regulada en los arts. $1975^{\circ}$ y $1976^{\circ}$ c.c., tiene como antecedente al Art. $1142^{\circ 5}$ del c.c. de 1936 , el cual, a su vez, sigue el Art. $79^{\circ 6}$ del proyecto franco-italiano de 1927.

La causalidad, tratada en el Art. $1321^{\circ}$ C.c., se remonta al Art. $1323^{\circ}$ del c.c. de 1936, al Art. $100^{\circ 8}$ el proyecto franco-italiano de 1927, al Art. $1265^{\circ 9}$ del c.c. de 1852 y al Art. $1151^{\circ 10}$ del c.c. francés de $1804 .{ }^{11}$

De esta apretada comparación, podemos observar que, tanto el Código Civil peruano de 1984, como el Código Civil italiano de 1942, en materia de responsabilidad civil, provienen de un tronco común, que es el

4Que sanciona que uel incapaz está obligado por sus actos ilícitos, a condición que haya obrado con discernimiento".

$5 \mathrm{El}$ cual, a la letra dice: “El padre, en su defecto, la madre y el tutor o curador son responsables por el daño que causen sus hijos menores o personas sujetas a su guarday.

6 Cuyo primer párrafo establece que «el padre, a falta de este, la madre y el tutor son responsables del daño ocasionado por el acto ilícito de los hijos menores que habiten con éstos».

7 El cual, precisaba que "los daños y perjuicios de que responde el deudor son los previstos, o los que se hubiese podido prever al tiempo de constituirse la obligación y que sean consecuencia necesaria de su falta de cumplimiento. En caso de dolo responde el deudor de todos los que conocidamente se deriven de la falta de cumplimiento de la obligación, como efecto directo e inmediato".

8 Que sanciona que «aunque el incumplimiento de la obligación derive del dolo del deudor, los daños relativos a la pérdida sufrida y al lucro cesante no deben extenderse sino a las consecuencias directas del incumplimiento. Aunque el incumplimiento de la obligación derive del dolo del deudor, los daños relativos a la pérdida sufrida y al lucro cesante no deben extenderse sino a las consecuencias directas del incumplimiento".

9 El cual, a la letra, decía: «El que celebra un contrato, no solo está obligado a cumplirlo, sino también a resarcir los daños que resulten directamente de la inejecución o contravención por culpa ó dolo de la parte obligada».

10 Que regula que «incluso en el caso en que el incumplimiento de la convención resulte del dolo del deudor, los daños y perjuicios no deben comprender, con respecto a la pérdida sufrida por el acreedor, y a la ganancia de que haya sido privado, sino aquello que sea consecuencia inmediata y directa del incumplimiento de la convención".

11 Sobre los antecedentes de este artículo, Mario Castillo Freyre, «Del Derecho de Obligaciones en el Perú", en: Instituciones del Derecho Civil Peruano (Versión Histórica), coordinador Guevara Pezo, Tomo III, Fundación M. J. Bustamante de la Fuente y UNIFE, Lima, 1996, pp. 1785 y 1786. 
Code Napoleon y el proyecto franco-italiano de 1927. Por ello, resulta sumamente importante confrontar cómo han sido interpretados ambos modelos jurídicos.

\section{La responsabilidad civil de los incapaces y sus representantes} legales: alcances $\mathrm{e}$ incoherencias

\subsection{La imputabilidad o capacidad de imputación de los denomina- dos incapaces}

Para la responsabilidad civil, la imputabilidad o "capacidad de imputación", es la aptitud del sujeto de derecho de ser responsable por los daños que ocasiona, ${ }^{12}$ lo cual para el ordenamiento jurídico nacional, se da cuando el sujeto tenga discernimiento (arts. $458^{\circ}$ y $1975^{\circ}$ c.c.). Comparto la opinión de quien sostiene que, "en un sentido más lato, el término imputabilidad ha entrado en el lenguaje como un sinónimo de referibilidad, de vinculación». ${ }^{13}$ Se afirma, con razón, que al negar la responsabilidad del incapaz (de querer y entender para el sistema italiano, privado de discernimiento para el nuestro) se "está entendiendo a la capacidad como una condición de la responsabilidad, pero no de la culpaw. ${ }^{14}$ En mi opinión, habrá responsabilidad sin culpa; pero no responsabilidad sin capacidad de imputación. En el caso de la responsabilidad sin culpa (objetiva) estarán los representantes legales de aquel que, careciendo de capacidad de imputación, causó el daño.

12 Hay un sector de la doctrina que se refiere a la capacidad extra-contractual, entendiendo como tal a "la idoneidad para ser sujetos activos de responsabilidad civil. Tal capacidad compete a las personas físicas y a los entes dotados de subjetividad jurídica» (Bianca, Diritto civile, 5, La Responsabilità, Giuffrè, Milano, 1994, p. 631). En sentido contrario, quien afirma que la imputabilidad es un fenómeno "propio solo de la persona física, mientras no lo es de la persona jurídica o de los entes de hecho, respecto a los cuales puede haber relevancia con el único efecto de comprobar el concurso de la responsabilidad por parte de quien han actuado en su nombre" (Franzoni, Fatti Illeciti, Zanichelli- Il Foro Italiano, Bologna-Roma, 1993, p. 319).

13 Franzoni, op. cit., p. 315.

14 Corsaro, "Culpa y responsabilidad civil: La evolución del sistema italiano", en: Estudios sobre la Responsabilidad Civil, traducción y edición a cuidado de León Hilario, Ara, Lima, 2001, p. 172. El autor afirma que «la obligación de resarcir puede encontrar su origen incluso al margen de la voluntad del evento" (op. cit., p. 173). 
Para el Art. $20^{\circ}$ código penal, está exento de responsabilidad penal, entre otros supuestos: "el que, por anomalía psíquica, grave alteración de la conciencia, o por sufrir alteraciones en la percepción, que afectan gravemente su concepto de la realidad, no posea la facultad de comprender el carácter delictuoso de su acto o para determinarse según esta comprensión" (inc. 1), así como el menor de 18 años (inc. 2), (modificado por la Ley No 264447, del 21.04.95).

El art. 1974 c.c., establece que:

«si una persona se halla, sin culpa, en estado de pérdida de conciencia, no es responsable por el daño que causa. Si la pérdida de conciencia es por obra de otra persona, esta última es responsable por el daño que cause aquellan. ${ }^{15}$

Para un sector de la doctrina, a propósito del modelo italiano, el fundamento de la norma "no es la ausencia de un elemento constitutivo del ilícito, sino una primaria razón de protección del incapaz. La incapacidad natural, precisamente, es un eximente personal de responsabilidad sancionada a tutela del incapaz». ${ }^{16}$ Entonces, en lo que a estado de salud mental

15 Este artículo se inspira en el Art. $2046^{\circ}$ del homólogo italiano, el cual establece que: "no responde de las consecuencias del hecho dañoso quien no tenía la capacidad de entender o querer al momento en el cual lo cometió, a menos que el estado de incapacidad derive de su culpa".

Se explica que "la capacidad de entender se pondría, [...], como la aptitud para orientarse según una percepción no equívoca de la realidad. La capacidad de querer consistiría, en cambio, en el poder controlar los impulsos a actuar, donde, justamente, la voluntad se entiende libre cuando el sujeto logra ejercitar poderes de inhibición y controb) (Monateri, "La Responsabilità Civiles en: Trattato di Diritto Civile, dirigido por Sacco, UTET, Torino, 1998, pp. 263-264).

Se observa como diferencia que el modelo peruano, al referirse al estado de inconciencia, solo hace alusión a la incapacidad de entender y no a aquella de querer. Por consiguiente, si una persona en perfecta conciencia de sus actos, actúa -por ejemplo- bajo el influjo de psicofármacos, vale decir, con plena conciencia, su conducta dañosa no sería comprendida dentro de los alcances del Art. 1974| y en consecuencia, sería responsable ex Art. 1969|o 1970| c.c., según sea el caso (De Trazegnies Granda, La responsabilidad extracontractual, Vol. IV, Tomo I, Fondo Editorial de la PUCP, Lima, 1988, pp. 390-391). Discrepo de esta opinión, el concepto de discernimiento tiene que entenderse en un sentido amplio, de tal manera que comprenda tanto el aspecto cognoscitivo como el volitivo.

16 Bianca, op. cit., p. 656. 
se refiere, la falta de imputación penal coincide con la civil, la cual se basa en el parámetro del discernimiento. En materia de edad, la diferencia entre la imputación penal y la proveniente de la responsabilidad civil, es que la primera es a partir de los dieciocho (18) años y, en la civil, a partir que el menor tenga discernimiento. En efecto, el Art. $458^{\circ}$ c.c., modificado por la Ley No 27184 , del 18.10.99, precisa que:

«el menor capaz de discernimiento responde por los daños y perjuicios que causan.

Sin mucha fatiga, se puede observar que un sujeto puede no ser imputable penalmente; pero sí a nivel de responsabilidad civil. Se puede observar que, en materia civil, «la edad, de por sí, no es un dato suficiente para excluir la imputabilidad, debiendo ser comprobados, por separado, el desarrollo intelectual, la fuerza del carácter, la ausencia de enfermedades». ${ }^{17}$ En suma: todos aquellos elementos que permitan comprobar la presencia de discernimiento en el sujeto. Si bien es cierto que el Art. $1974^{\circ}$ c.c., regula el estado de inconciencia transitorio, hay un común denominador con los artículos que regulan la responsabilidad civil de los denominados incapaces. Así, el Art. $458^{\circ}$ c.c. tiene que ser interpretado sistemáticamente con el Art. $1975^{\circ}$ c.c., que establece que, cuando el incapaz de ejercicio con discernimiento ocasiona un daño, este es responsable en vía solidaria con su representante legal. ${ }^{18}$ Cuando el incapaz sin discernimiento es autor de un hecho dañoso, responde solo su representante legal (Art. 1976), previéndose una indemnización equitativa cuando la víctima no haya podido obtener una reparación. Esta indemnización será autorizada por el juez en vista de la situación económica de las partes (Art. 1977\%). En mi opinión, se entienden como sinónimos, en tanto estados psicológicos, la conciencia a la cual se refiere el Art. $1974^{\circ}$ y el discernimiento reclamado en los arts. $1975^{\circ}$ y $1976^{\circ}$. La diferencia existente entre estas dos realidades responde a un criterio de temporalidad: en el primer caso se trata de una situación transitoria y en el segundo es permanente. Otra diferencia es la naturaleza de cada supuesto de responsabilidad o de irresponsabilidad: el del Art. $1974^{\circ}$, por sus características, encaja más en un supuesto

17 Franzoni, op. cit., p. 318.

18 En este mismo sentido, Arias-Schreiber Pezet, con la colaboración de Arias-Schreiber Montero y Varsi Rospogliosi, Exégesis del Código Civil Peruano de 1984, Tomo VIII, Derecho de Familia, Sociedad Paterno-Filial, Gaceta Jurídica, Lima, 2001, p. 219. 
originado por un caso fortuito, mientras que el de los arts. $1975^{\circ}$ y $1976^{\circ}$ se refiere, en línea de principio, a sujetos judicialmente declarados incapaces $y$, por ello, dignos de protección y tutela. Entonces, a efectos de atribuir responsabilidad civil, el sujeto capaz o incapaz, debe tener discernimiento.

Debe de distinguirse, entonces el elemento de la imputabilidad del de la culpa (como perteneciente al elemento, factor de atribución). El análisis de la culpa, obviamente si se entiende a la misma de manera objetiva, no tiene como objeto "el componente psíquico de la conducta del autor». ${ }^{19} \mathrm{El}$ análisis de la culpa «se refiere a la disconformidad de la conducta, respecto de un canon de comportamiento socialmente dado o establecido normalmentem. ${ }^{20}$

La doctrina no es pacífica cuando la responsabilidad (o irresponsabilidad) del incapaz (o del capaz que se encuentra en estado transitorio de inconciencia) confluye con los supuestos de responsabilidad objetiva, como es el caso de la responsabilidad derivada del ejercicio de actividades (o de las cosas) riesgosas o peligrosas (Art. $1970^{\circ}$ c.c.). Sobre el particular existen, al menos, dos posiciones:

a) Que las normas que regulan la responsabilidad de los sujetos incapaces (o de los capaces en estado transitorio de inconciencia) solo se aplican en supuestos de responsabilidad subjetiva (como los arts. $1969^{\circ} \mathrm{c} . \mathrm{c}$., $1978^{\circ}$ c.c. o $1982^{\circ}$ c.c.) y, en el caso de supuestos de responsabilidad objetiva, el sujeto incapaz (o el capaz en estado transitorio de inconciencia), es responsable, por cuanto este particular status es irrelevante a efectos de la atribución de responsabilidad. Así, se afirma que «la conducta del que ejercita la actividad peligrosa constituye un simple antecedente del evento dañino, que le es adscrito independientemente de cualquier aspecto de sus condiciones psico-físicas, de tal manera que el que ejerce estas actividades está llamado a responder, aunque sea menor o incapaz natural». ${ }^{21}$ En

19 Franzoni, op. cit., p. 319.

20 Franzoni, op. cit.

21 Monateri, op. cit., p. 1010. En este mismo sentido, Franzoni, op. cit., p. 326. A nivel de doctrina nacional, se afirma que, «cuando un daño se produce mediante un bien o una actividad riesgosos, poco importa que el sujeto se encuentre privado de discernimiento o no para hacerlo responsable del daño. En este caso, no responde por culpa sino objetivamente o, si se prefiere, en razón de la teoría del riesgo. Por consiguiente, las alteraciones en la formación de la culpa no afectan su obligación de reparar el dañon (De Trazegnies, op. cit., p. 408). 
Francia, para el Code, después de la reforma de la Ley No 68-5/68, está obligado al resarcimiento incluso aquel que ha causado el daño en el momento en el cual se encontraba bajo el dominio de una alteración mental (Art. 489-2). En concordancia con este dispositivo, también el incapaz es responsable por el daño ocasionado por las cosas (Art. 1384-1) y de daños ocasionados por los animales, cuando el incapaz es el guardián (Art. $\left.1385^{\circ}\right)^{22}$. La jurisprudencia considera que la responsabilidad del disminuido ex Art. 489-2 no sea una fattispecie autónoma del Art. 1382० (que regula el principio general de la responsabilidad civil) ni del Art. $1383^{\circ}$ (responsabilidad en los casos de negligencia o imprudencia). ${ }^{23}$ Sobre la posibilidad de extender este tipo de responsabilidad también a los menores de edad la doctrina se ha dividido ${ }^{24}$ y la jurisprudencia ha asumido una posición elástica. ${ }^{25}$ Cuando el menor sufre de una enfermedad mental y ocasiona daños, no es aplicable el Art. 489-2. ${ }^{26}$ La simple pérdida de conocimiento, originada por un disturbio de carácter físico, no es considerada equivalente a una alteración mental y en consecuencia, los alcances del Art. 489-2 se limitan a los daños ocasionados por los enfermos de

22 Hay quien considera que esta solución puede parecer "poco equilibrada» (Patti, Ancora sul favor del diritto civile per gli incapaci (e su una innovazione, di segno opposto, dell'ordinamento francese) en: Riv. dir. civ., 1983, p. 646). Se sostiene también que el legislador francés haya optado por una vía peligrosa y se hace una invitación a la prudencia para el precio a pagar por la "puesta en libertad" en el tráfico jurídico del enfermo de mente (Autorino Stanzione, "Sulla responsabilitá dell'infermo di mente nell'esperienza francese", en: Riv. dir. civ., 2, 1991, pp. 368-369).

23 CAS., 2a., 04.05.77, en Venchiarutti, "La responsabilità civile degli infermi dei mente in Francia", en: Riv. crit. dir. priv., 1986, p. 510. Por consiguiente, de frente a una doctrina minoritaria que defiende la interpretación restrictiva del Art. 489-2, la jurisprudencia se ha alineado a aquel sector de la doctrina que es favorable a una interpretación extensiva del citado artículo (Petrelli, "La responsabilità civile dell'infermo di mente nell'ordinamento francese", en: Riv. dir. civ., 1991, p. 85).

$24 \mathrm{Cfr}$. Zeno-Zencovich, "La colpa oggettiva del malato di mente: le esperienze nordamericana e francesen en: Resp. civ. e prev., 1986, p. 10.

25 Bussani, La colpa soggettiva, CEDAM, Padova, 1991, p. 170. Aunque si, en línea de principio, se puede afirmar que, a partir de la Asamblea Plenaria de la Corte de Casación del 09.05.84, que ha tratado cinco decisiones en las cuales se encontraban implicados menores, el menor incapaz de entender y de querer es responsable civilmente, equiparando su posición con aquella del enfermo de mente. Curiosamente, el fundamento doctrinario de esta decisión se encuentra en los arts. $1382^{\circ}$ y $1384^{\circ}$ y no en el Art. 489-2 (Venchiarutti, op. cit., p. 519 y Petrelli, op. cit., p. 94).

26 CAS., 1a., 20.07.76, en: Venchiarutti, op.cit., p. 516 y en Petrelli, op. cit., p. 87. 
mente. ${ }^{27}$ Incluso, a nivel de doctrina nacional se advierte la necesidad de una apreciación in abstracto de la culpa, de manera tal que también los sujetos sin discernimiento sean civilmente responsables, en cuanto no se adecuen al standard del hombre razonable. De este modo se superaría la concepción subjetiva de la culpa. ${ }^{28}$

b) Que tanto en los supuestos de responsabilidad subjetiva como objetiva, se aplican la normatividad de los sujetos incapaces (o de los capaces en estado transitorio de inconciencia), por cuanto el requisito previo indispensable para atribuir responsabilidad (objetiva o sujetiva) es la capacidad de imputación (o imputabilidad) del sujeto. Defendiendo esta posición, se observa que «la exención de responsabilidad tiene fundamento, no en la falta de culpa, sino en la exigencia de tutela de este sujeto: exigencia que permanece firme cuando el sujeto se encuentre realizando actividades peligrosas". ${ }^{29}$ En efecto, "gravar al incapaz con la obligación de resarcimiento del daño significaría hacerlo víctima del daño, significaría descuidar un interés que no es menos merecedor de tutela que el interés del dañado. La elección del ordenamiento está en el sentido de privilegiar este interés, y la elección se mantiene, porque el principio de salvaguarda del interés del incapaz responde a una exigencia siempre advertida por la conciencia social». ${ }^{30}$

Yo suscribo la segunda posición. En efecto: es cierto que el factor de atribución objetivo prescinde de la intencionalidad del agente dañino; pero no se debe olvidar que un prius frente a todo el sistema de responsabilidad civil es el de la capacidad del agente dañino. Repito, en la responsabilidad objetiva, es irrelevante la culpa (o el dolo) como factor de atribución; pero no la capacidad de imputación del agente dañino. Hecha esta diferencia, en mi opinión esta discusión se convierte en un falso problema, el cual se disuelve interpretando coherente y sistemáticamente los arts. $1970^{\circ}, 1975^{\circ}, 1976^{\circ}$ y $1977^{\circ}$. En efecto, si el incapaz tiene discernimiento, responderá solidariamente con su representante legal; si no tiene discernimiento, responde su representante legal y, si el representante legal no tiene dinero, en vía equitativa se responde con el patrimonio del incapaz sin discernimiento. No se olvide, además, que la responsabilidad

27 CORTE SUP., 2a. cámara, 04.02.81 en Venchiarutti, op. cit., 517 y en Petrelli, op. cit., p. 95 .

28 Fernando de Trazegnies Granda, op. cit., p. 417.

29 Bianca, op. cit., p. 712.

30 Bianca, op. cit., p. 657. 
objetiva admite supuestos de ruptura del nexo causal para los «capaces» e «incapaces» (Art. 1972| c.c.).

Volviendo al Art. $1974^{\circ}$ c.c., queda claro que si el dañante generó una situación de "incapacidad autoprovocada", ${ }^{31}$ vale decir, provocó su estado de inconciencia (porque se embriagó previamente) deberá responder frente a la víctima. Como también lo hará el que provocó dicho estado de inconciencia, evidentemente, si se llega a probar. Así, en supuesto del el caso de los accidentes automovilísticos «si el malestar (que genera el estado de inconciencia) durante el manejo sea del todo imprevisible no podrá ser pronunciada la responsabilidad; por el contrario, el cardiopático o el epiléptico, que conocen bien la sintomatología de su enfermedad, no podrán excusarse por su estado, a efectos de acreditar la no imputabilidad en el momento del hechom. ${ }^{32}$ Ello prueba que, para que califique un supuesto en el Art. $1974^{\circ}$, el estado de inconciencia debe ser originado por un caso fortuito, reconducible al Art. $1315^{\circ}$ c.c. En efecto, en los supuestos mencionados, nos encontramos en situaciones imprevistas; pero no imprevisibles. ${ }^{33}$

Insisto, lo importante es determinar si es más justo un modelo que tutele efectivamente a la víctima del daño ocasionado por una persona, aunque se encuentre en un estado de pérdida de la conciencia, en menoscabo de la tutela que merece la situación momentánea de la incapacidad de entender, que prevé el código peruano, la cual se traduce en la falta de culpa del agente dañoso (Art. 1974\%).

Constituye una tarea no fácil la de tratar de equilibrar estos dos intereses. Una premisa para ello es la de no dejarse seducir de una manera absoluta por la corriente que propone cambiar la atención hacia la víctima. ${ }^{34}$ En efecto, frente al sistema francés, que responsabiliza al privado de discernimiento por sus actos ilícitos y el sistema italiano, que establece como condición para atribuir la responsabilidad civil, la de tener capaci-

31 Monateri, op. cit., p. 265.

32 Franzoni, op. cit., 321.

33 Monateri, op. cit., 269.

34 Esta idea, para nada nueva, ha sido ya evidenciada en estos términos: «el cambio de atención del autor del daño a la víctima, a ver bien, no es solo el contenido de una siempre más advertida necesidad de seguridad, sino es además la consecuencia inevitable de una situación en la cual la búsqueda de un autor material del daño arriesga a menudo de no dar ningún resultadon (Rodotà, Ilproblema della responsabilità civile, Giuffrè, Milano, 1964, p. 23). 
dad de querer y de entender, el legislador peruano ha optado, de una manera correcta, por esta última posición. El hecho de pretender que siempre el sujeto dañado sea indemnizado puede hacer que se cambien los roles de las "víctimas de sangre" por los de las "víctimas económicas». ${ }^{35}$ Ello, en la medida que debemos entender que la responsabilidad civil debería obedecer a criterios de justicia distributiva, en vez que a criterios de justicia retributiva. ${ }^{36}$

Se ha puesto en evidencia que las nuevas directivas de la ciencia psiquiátrica se orientan hacia la resocialización del enfermo de mente a través de los nuevos tratamientos psiquiátricos con el auxilio del recurso a la responsabilidad individual. Los psiquiatras modernos consideran que el hecho de considerar inimputable a una persona que sufre de disturbios psíquicos equivale a decir que la enfermedad - y no el sujeto- es la autora del acto ilícito, lo que significa, en otras palabras, no responsabilizar a una persona, hacerla sentir diversa y cada vez más anormal. ${ }^{37}$

Frente a esta opinión debemos tener en cuenta que el modelo jurídico diseñado por el legislador peruano en lo que a materia de responsabilidad civil se refiere, se basa en la conjunción de dos elementos, uno subjetivo (imputación de la responsabilidad a un sujeto) y otro objetivo (lesión del interés ajeno).$^{38}$ En este orden de ideas, si se debe responsabilizar a un sujeto, este debe tener la libertad (que implica también el discernimiento) necesaria para que asuma las consecuencias de los actos que realiza y, si se quiere hablar en deliciosos términos económicos, internalizar los costos de sus daños. La propuesta de responsabilizar al enfermo de mente por parte de cierto sector de los psiquiatras modernos me deja un tanto perplejo, porque cuesta creer que si un sujeto no es capaz de entender el acto ilícito que cometió, mucho menos entenderá por qué tiene que asumir

35 La expresión ha sido tomada, aunque el autor la utiliza en otro sentido, de Ordoqui Castilla, «Pautas y criterios para la avaluación del daño a la persona», en: Daño a la persona. Pautas jurisprudenciales, Ediciones Del Foro, Montevideo, 1996, p. 94.

36 Sobre la diferencia de estos tipos de justicia, cfr. Perlingieri, Il diritto civile nella legalità costituzionale, ESI, Napoli, 1991, pp. 91-92.

37 Así, Visintini, a propósito del modelo jurídico italiano, en: Trattato breve della responsabilità civile, CEDAM, Padova, 1996, p. 475, ahora en español, en: Tratado de la responsabilidad civil, traducido por Kemelmajer De Carlucci, con la colaboración de Atienza Navarro, Bossio, Espinoza Espinoza, Longhin y Woolcott Oyagüe, Tomo 2, Astrea, Buenos Aires, 1999, pp. 164-165.

38 Visintini, op. cit., p. 16. 
las consecuencias de este, lo que pone en seria discusión, la pretendida función resocializadora del recurso de la responsabilidad individual del enfermo de mente. ${ }^{39}$

\subsection{La responsabilidad objetiva de los representantes legales de los denominados incapaces con discernimiento}

En el caso de los representantes legales de los declarados incapaces con discernimiento, existe un problema, que ha sido originado por el propio legislador peruano que no tuvo cuidado de interpretar adecuadamente los modelos legislativos diseñados por sus homólogos. En efecto, el Art. $2191^{\circ}$ del c.c. peruano de 1852 sigue al Art. $1384^{\circ}$ del Code al establecer la responsabilidad del padre $y$, a falta de este, de la madre por los daños que causen sus hijos (el primero precisa que estén bajo su patria potestad y el segundo que habiten con ellos); pero, regula que el guardador responde "por los perjuicios que causen sus menores ó los incapaces que tienen a su cargo". Este precepto se repite en el Art. $1142^{\circ}$ del c.c. peruano de 1936, al establecer que "el padre, en su defecto, la madre y el tutor o curador son responsables por el daño que causen sus hijos menores o personas sujetas a guarda». Sin embargo, siguiendo la influencia Art. $75^{\circ}$ del proyecto franco-italiano, se establece la imputabilidad del incapaz con discernimiento. ${ }^{40}$ De ahí que el Art. $1142^{\circ}$ debía ser interpretado con el Art. $1139^{\circ}$ del c.c. de 1936 , por cuanto, al establecer que "el incapaz queda obligado por sus actos ilícitos siempre que hubiere procedido con discernimiento", surgía la responsabilidad conjunta del incapaz con discernimiento y de su representante legal. Ello fue duramente criticado por

39 En este sentido, se afirma que «el resarcimiento del daño no es una obligación personal de la cual se pueda abstractamente hipotizar una positiva función estimulante frente a quien sufra su ejecución. Se trata, más bien, de un remedio de naturaleza económica, que se traduce en una obligación pecuniaria y que es, por consiguiente, insusceptible de incidir sobre la psiche de quien no está en grado de entender o de querern (Bianca, op. cit., p. 660).

$40 \mathrm{El}$ criterio de la imputabilidad en materia de responsabilidad civil, basada en el discernimiento, fue herencia de la jurisprudencia francesa tradicional. Así, se afirmaba que "para los tribunales (franceses), la responsabilidad civil supone el discernimienton (H., L. y J. Mazeaud, Lecciones de Derecho Civil, Parte Segunda, Volumen II, La Responsabilidad Civil. Los Cuasicontratos, traducida por Alcalá-Zamora y Castillo, Ediciones Jurídicas Europa-América, Buenos Aires, 1960, p. 116). No se olvide que la versión original en francés de Leçons de Droit Civil, data de 1955. 
una autorizada doctrina nacional de la época. Así, se afirmó lo siguiente: "creemos que la responsabilidad indirecta de los curadores no es operante en el caso de los pródigos (inc. $4^{\circ}$ del Art. $555^{\circ}$ c.c. de 1936), de los que incurren en mala gestión (inc. $6^{\circ}$ del Art. $555^{\circ}$ c.c. de 1936), y de los que sufren interdicción civil como consecuencia de una sanción penal (inc. $7^{\circ}$ del Art. $555^{\circ}$ c.c. de 1936), ya que a estas personas no se les somete a curatela por el hecho de estar privados de raciocinio en su conducta habitual, sino por otras causas que razonablemente no es posible concomitar con la pérdida de facultad. Sus actos ilícitos, por tal motivo, les serán plenamente imputados, pues el daño que causaron no se descubre que pueda ser efecto de la culpa del curador, que presuntamente pudiera haber cometido en el ejercicio de su función». ${ }^{41}$

El Código Civil italiano, cuerpo normativo que, como se mencionó, ha sido una de las "fuentes inspiradoras" de nuestro código civil, en la primera parte del Art. $2047^{\circ}$ establece que «en caso del daño ocasionado por la persona incapaz de entender y de querer, el resarcimiento es debido por quien está obligado al cuidado del incapaz, salvo que pruebe no haber podido impedir el hecho". El código civil italiano, a diferencia del peruano, regula en el Art. $414^{\circ}$ la interdicción (para quienes se encuentran en condiciones de habitual enfermedad de mente que los hace incapaces de cuidar sus propios intereses), en el Art. $415^{\circ}$ la inhabilitación (para los casos en los cuales el estado de la persona no es tan grave como para declarar la interdicción y para los pródigos, los toxicómanos, así como ebrios habituales que exponen a su persona y a su familia a graves perjuicios económicos) y la incapacidad denominada natural (de querer y entender). Los alcances del Art. $2047^{\circ}$ deben ser entendidos para los que estén obligados a cuidar a los (por hablar en términos de nuestro código) «faltos de discernimiento", que no son, necesariamente, los representantes legales de los interdictos ni (mucho menos) de los inhabilitados.

El actual Art. $1975^{\circ}$ del c.c. peruano, siguiendo (y empeorando) este error, establece que:

"La persona sujeta a incapacidad de ejercicio queda obligada por el daño que ocasione, siempre que haya actuado con discernimiento. El representante legal de la persona incapacitada es solidariamente responsable».

41 Rey De Castro, La responsabilidad civil extracontractual. Estudio Teórico y Práctico del Derecho Nacional y Comparado, s/e, Lima, 1972, p. 231. 
Nótese que este numeral comprende dentro de la expresión incapaz a los todos los sujetos elencados en los arts. $43^{0^{42}}$ y $44^{0^{43}}$ (se entiende, con discernimiento), llegándose al exceso de responsabilizar (solidariamente) a los representantes legales de todos los incapaces con discernimiento: incluyendo (como igualmente se advirtió en su oportunidad, al comentar el Art. $1142^{\circ}$ del c.c. de 1936) al pródigo, al mal gestor y al que lleva anexa la inhabilitación civil, en los cuales el discernimiento no ha sido la causa para la declaración de incapacidad. El supuesto de los ebrios habituales, los toxicómanos, los mayores de dieciséis y menores de dieciocho años, los retardados mentales y los que adolecen de deterioro mental, debería ser visto caso por caso. Ello resulta de suma importancia, por cuanto la responsabilidad del representante legal es objetiva y el legislador no ha debido ser tan severo en el primer grupo de supuestos: para el pródigo y el mal gestor, el representante debe ser responsable de los actos de disposición patrimonial de los mismos y para el que lleva anexa la inhabilitación civil, el representante es responsable por la protección que merece la persona y su familia, debido a la limitación de su derecho a la libre circulación. Resulta totalmente disuasivo responsabilizar de una manera tan laxa a este tipo de representantes legales. Es por ello que se impone una interpretación restrictiva del Art. $1975^{\circ}$ c.c., en el sentido que solo se configurará la responsabilidad solidaria del representante legal por los daños del incapaz con discernimiento que esté bajo su cuidado personal. Con ello, no se pretende establecer una responsabilidad subjetiva del representante legal, sino una responsabilidad objetiva imputable a quien se halla jurídicamente obligado a controlar a un sujeto con capacidad res-

$42 \mathrm{El}$ cual establece que «son absolutamente incapaces:

1. Los menores de dieciséis años, salvo para aquellos actos determinados por la ley.

2. Los que por cualquier causa se encuentren privados de discernimiento.

3. Los sordomudos, los ciegosordos y los ciegomudos que no pueden expresar su voluntad de manera indubitable».

43 Que precisa que «son relativamente incapaces:

1. Los mayores de dieciséis y menores de dieciocho años de edad.

2. Los retardados mentales.

3. Los que adolecen de deterioro mental que les impide expresar su libre voluntad.

4. Los pródigos.

5. Los que incurren en mala gestión.

6. Los ebrios habituales.

7. Los toxicómanos.

8. Los que sufren pena que lleva anexa la interdicción civil». 
tringida, haciéndole internalizar los daños que este ocasiona, por cuanto "objetivamente", se encuentra en la mejor posición para evitarlos (ya que lo tiene «bajo su cuidado"). Ello, evidentemente, implica un mayor esfuerzo de nuestros jueces al delimitar los alcances de las facultades de los representantes legales en la sentencia que declara la interdicción de una persona, los cuales deberán ser precisados caso por caso. ${ }^{44}$

Por ello, comparto la opinión de quien sostiene que «lamentablemente, el Código no se ha planteado estas cuestiones que, no obstante, son reales y fundamentales; particularmente si la tendencia moderna adopta una perspectiva objetivista. Las normas de los artículos $1975^{\circ}$ y $1976^{\circ}$ no distinguen ahí donde deberían haber distinguido entre distintas situaciones con diferente estructura de lazos humanos, lealtades y garantías: que un padre responda por los daños cometidos por el hijo, parece normal; en cambio, que un curador - que a veces es el abogado de la familia o un funcionario - responda solidariamente por todos los daños automovilísticos cometidos por el pródigo o por el que incurre en mala gestión o aun por el sordomudo, la cosa no parece tan clara" ${ }^{45}$. Esta posición sigue el lineamiento que ya había sido trazado por la autorizada doctrina, ya citada, que comentara el Art. $1142^{\circ}$ del c.c. peruano de 1936.

\section{La pretendida disparidad de tratamiento de la relación causal entre la responsabilidad contractual y la extracontractual}

Para un sector de la doctrina argentina, «cuando hablamos de un hecho aludimos a una modificación del mundo exterior que sucede en un momento dado y en cierto lugar, con la intervención de personas y cosas que constituyen los elementos actuantes. Sin embargo, cada hecho no es sino un eslabón en una cadena causal en la que se suceden inexorablemente hechos que son antecedentes de aquel y hechos que son su consecuencia». ${ }^{46}$ Con razón, se afirma que la relación de causalidad "no puede ago-

44 Sobre el particular, permítaseme remitir a Espinoza Espinoza, La capacidad civil de las personas naturales. Tutela jurídica de los sujetos débiles, Grijley, Lima, 1998, p. 119 , en el cual, siguiendo el modelo jurídico de un sector del common law, proponía la utilización de formularios en los cuales se delimiten específicamente las obligaciones de los representantes legales de los denominados «incapaces».

45 Fernando de Trazegnies Granda, op. cit., p. 414.

46 Bustamante Alsina, Teoría General de la Responsabilidad Civil, Abeledo-Perrot, Buenos Aires, novena edición, 1997, p. 267. 
tarse en una relación de tipo naturalista entre causa y consecuencias, sino se debe conducir y resolver, en los términos de un juicio idóneo a expresar la carga de los valores ínsita en la afirmación de responsabilidad». ${ }^{47}$ Por ello, «la relación entre causalidad y responsabilidad es una relación difícil de describir y cambiante con los tiempos y las circunstanciasm. ${ }^{48}$ Debe tenerse en cuenta que, tanto el Art. $1969^{\circ}$ c.c y como en el $1970^{\circ}$ c.c. se refieren a quien causa un daño, ello quiere decir que tanto en la responsabilidad subjetiva como en la objetiva está presente este elemento.

Se afirma que en materia de responsabilidad civil extracontractual o aquiliana se acoge la teoría de la causa adecuada (Art. $1985^{\circ}$ c.c.) y en inejecución de las obligaciones se asume la teoría de la causa próxima (Art. $1321^{\circ}$ c.c., segundo párrafo), el cual establece que:

"el resarcimiento por la inejecución de la obligación o por su cumplimiento parcial, tardío o defectuoso, comprende tanto el daño emergente como el lucro cesante, en cuanto sean consecuencia inmediata y directa de tal inejecución" (el subrayado es mío).

A propósito del Art. $1223^{\circ}$ del c. c. italiano (que, al igual que el Art. $1321^{\circ}$ de nosotros, se ha inspirado en el Art. $1151^{\circ}$ del Code y, de alguna manera, en el Art. $100^{\circ}$ del proyecto franco-italiano), se sostiene que esta fórmula se refiere a la «determinación del daño" y no a la inmediatez de la causa. ${ }^{49}$ En efecto, «una cosa es emplear la causalidad con el fin de imputar un hecho a un sujeto, en el concurso de otros factores, como la culpa, el dolo, la preposición (de un tercero), el ejercicio de una actividad riesgosa, la custodia, el ser propietario (aquí se debe responder a la pregunta: ¿quién ha sido?) y otra cosa es emplear la causalidad para estimar el daño patrimonial, es decir, para determinar la relevancia jurídica de las consecuencias económicamente desfavorables dependientes del hecho ilícito (aquí se debe responder a la pregunta: ¿cuánto debe pagar el responsable?)". ${ }^{50}$

47 Scognamiglio, voz Responsabilità Civile, en: Novísimo Digesto Italiano, XV, UTET, Torino, 1968, p. 651.

48 Alpa, Responsabilidad civil y daño. Lineamientos y cuestiones, traducción a cura de Espinoza Espinoza, Gaceta Jurídica, Lima, 2001, p. 331.

49 Scognamiglio, op. cit.

50 Franzoni, Fatti Illeciti, Zanichelli- Il Foro Italiano, Bologna-Roma, 1993, p. 86. 
En atención a ello, a propósito de la redacción del Art. $1223^{\circ}$ del c.c. italiano, autorizada doctrina sostiene que «es claro que se trata de fórmulas metafóricas, las cuales no pueden ser tomadas al pié de la letra». ${ }^{51}$ Un sector de la doctrina italiana sostiene que a lo que se quiere hacer referencia en el Art. $1223^{\circ}$ c. c. ita. es "a las hipótesis en las cuales el hecho hipotético dado por la ley, como fuente de responsabilidad, aunque no produzca en línea directa el daño, cree una situación tal, que a falta del mismo, no se habría producido». En consecuencia, «en estos casos, parece justo, teniendo en cuenta la finalidad de la ley, vincular a dicho acto, más allá de toda consideración sobre su proximidad, el evento dañino». ${ }^{52}$ Ello está en sintonía con aquella autorizada doctrina que afirma que "la función del Art. $1223^{\circ}$ del Código Civil es solamente descriptiva y está contenido en la norma simplemente para indicar la directiva del legislador, según la cual la reintegración del patrimonio del acreedor debe ser integral y atenerse a todos los perjuicios económicos sufridos por el damnificadom. ${ }^{53}$ En jurisprudencia, a propósito de la aplicación del Art. $1223^{\circ}$, no obstante su redacción, se prefiere hablar de «regularidad causal» (o causalidad adecuada), en el sentido que son considerados resarcibles los dańos que entran dentro de las consecuencias normales y ordinarias del hecho dañoso. ${ }^{54}$

De ello se desprende que el objeto del nexo causal tiene doble relevancia. ${ }^{55}$

51 Trimarchi, Causalità e danno, Giuffrè, Milano, 1967, p. 20. En este mismo sentido, De Cupis, El daño. Teoría general de la responsabilidad civil, traducido por Martínez Sarrion, Bosch, Barcelona, 1975, p. 260.

52 Scognamiglio, op. cit.

53 Visintini, Tratado de la Responsabilidad Civil, traducido por Kemelmajer De Carlucci, con la colaboración de Atienza Navarro, Bossio, Espinoza Espinoza, Longhin y Woolcott Oyagüe, Tomos 1 y 2, Astrea, Buenos Aires, 1999, p. 208. En este mismo sentido, se afirma que «la interpretación histórica y la ubicación sistemática del Art. $1223^{\circ}$ c.c. demuestran, en definitiva, que el criterio de las consecuencias inmediatas y directas, está dirigido a disciplinar el problema del quantum respondeatur, para establecer un límite a la resarcibilidad de los perjuicios, comprendidos en una única serie causal dañina vinculada al acto ilícito o al incumplimiento, por consiguiente, es extraño a la disciplina del concurso de causas y a la imputación del evento dañino a su autor" (Pinori, Il criterio legislativo delle conseguenze immediate e dirette, en Risarcimento del danno contrattuale ed extracontrattuale, a cura de Visintini, Giuffrè, Milano, 1999, p. 78).

54 Casación $N^{\circ}$ 4186, del 23.04.98, en: Responsabilità civile e previdenza, con Nota de Pellecchia, Giuffrè, Milano, 1998, p. 1409.

55 Salvi, La Responsabilità Civile, Giuffrè, Milano, 1998, p. 171. 
a) Para el aspecto del evento lesivo (causalidad de hecho o fáctica), se procede a la reconstrucción del hecho a los efectos de imputación de la responsabilidad.

b) Para el aspecto del daño resarcible (causalidad jurídica), se determinan las consecuencias dañosas que el responsable deberá resarcir.

Como correlato de ello, la finalidad de la causa es doble: «imputar al responsable el hecho ilícito y establecer la entidad de las consecuencias perjudiciales del hecho que se traducen en el daño resarcible». ${ }^{56}$ Sin embargo, se afirma que este binomio solo se trata de un uso lingüístico aceptable, porque tanto la causalidad natural como la jurídica, son "criterios de calificación normativam. ${ }^{57}$

En mi opinión, tanto en el Art. $1985^{\circ}$ como en el $1321^{\circ}$, se han confundido estos niveles, y me temo que ello se ha debido (nuevamente) al hecho de asimilar apresuradamente los modelos circulantes en otras experiencias jurídicas, sin tener en cuenta su interpretación doctrinaria ni su aplicación jurisprudencial. Ya hemos visto que nuestro Art. 1321 debido a sus raíces comunes, es similar al $1223^{\circ}$ del c. c. ita. En materia de responsabilidad aquiliana, el Art. $2056^{\circ}$ del Codice establece que el resarcimiento debido al dañado se debe determinar debido a las disposiciones de los arts. $1223^{\circ}, 1226^{\circ}$ y $1227^{\circ}$. ¿Ello quiere decir que, debido a la remisión que hace el Art. $2056^{\circ}$ al Art. $1223^{\circ}$, solo existe la causalidad próxima en el Codice? La respuesta correcta es la negativa: la jurisprudencia italiana acoge la teoría de la causalidad adecuada ullegando a comprender entre los daños resarcibles también a las consecuencias del ilícito que no entran en el ordinario curso de los eventos». ${ }^{58}$

56 Franzoni, op. cit., p. 89.

57 Salvi, op. cit., p. 172.

58 Bianca, op. cit., p. 131. El autor cita el caso, visto por el Tribunal de Milano, del 13.07.89, del conductor de una motocicleta, embestido e internado en un hospital, que sufre ulteriores lesiones, por haberse caído desde una ventana en un intento de fuga originado por las alteraciones psíquicas provocadas por el accidente (cit.). En el ámbito contractual, según Casación $\mathrm{N}^{\circ} 4236$, del 19.07.82, el daño "está circunscrito, en la exigencia de la búsqueda de un principio idóneo a seleccionar, entre las varias condiciones del daño, la que constituye una relación de causalidad, por el criterio de la causalidad adecuada (o regularidad causal), en el sentido que son resarcibles los daños inmediatos y directos y aquellos que, aún siendo mediatos e indirectos, entran, sin embargo, en la serie de las consecuencias normales y ordinarias del hecho: $y$ tal criterio tiende a coincidir con el de la previsibilidad del daño, entendida ésta como el juicio de probable suceso futuro, según 
En suma: propongo una interpretación del segundo párrafo del Art. $1321^{\circ}$ c.c. que, más allá de su literalidad, se entienda que no regula el aspecto de la relación de causalidad, sino el límite del quantum resarcitorio (causalidad jurídica), el cual, incluso, no debe ser interpretado ad pedem literae. $^{59}$

Quizá un caso nos ayude a entender cómo opera un adecuado análisis causal: una persona compra un pasaje aéreo y luego demanda por un millón de dólares americanos a la compañía de aviación. El pasajero se queja de que había dos escalas no informadas (lo que le ocasionó malestares de salud), así como que llegó tarde a una cita de negocios (no concretada) en New York, que al regreso no encontraron una de sus dos maletas, en la cual justamente estaba su libreta electoral (y por ello no pudo votar) y que, como consecuencia de ello, lo despidieron de su trabajo (por pedir dos permisos para regularizar su situación de omiso, por cuanto la maleta se la devolvieron dos días después de su arribo a Lima). En primera instancia, con resolución diez, del 29.10.99, se declara infundada la demanda. El análisis causal fue el siguiente:

«a que, respecto del dańo personal alegado, debemos tener presente que del tenor de la carta que corre a fojas trece se advierte que en ella no se señala causa alguna de despido $n i$ se ha aportado medio probatorio idóneo que vincule dicho despido al actuar de la demandada; además, que si el actor consideró arbitrario su despido tenía expedita la vía correspondiente para accionar por indemnización contra su empleadora ante el fuero correspondiente; también, concordando con el criterio asumido, debe tomarse en cuenta lo señalado en el artículo mil trescientos veintiuno del Código Civil, en el sentido, que el daño

la apreciación del hombre de diligencia normal, en el ámbito en el cual son conocidas, conocibles y previsibles las posiciones del hecho y las concausas que inciden en la producción y en el desarrollo del daño" (cit., p. 130).

59 Es bueno tener en cuenta que, cuando se redactó la exposición de motivos (auténtica, no oficial) se afirmó que el segundo párrafo del Art. $1321^{\circ} \mathrm{C}$. c., consigna el precepto que «la indemnización debe comprender todos los daños y perjuicios que sean consecuencia inmediata y directa del incumplimiento, trátese de daños y perjuicios previstos o no previstos" (el subrayado es mío) (Osterling Parodi con la colaboración de Cárdenas Quirós, Exposición de Motivos y Comentarios al Libro VI del Código Civil (Las Obligaciones), en: Comisión encargada del estudio y revisión del Código Civil, Código Civil, V, Exposición de Motivos y Comentarios, compilado por Revoredo de Debakey, s/e, Lima, 1985, p. 448). 
indemnizable debe ser consecuencia directa de la acción del demandado, lo que no se cumple en el presente caso, pues no existe relación alguna entre el transporte aéreo ejecutado y el despido arbitrario del actor, más aún si de su propia declaración de parte obrante en el acta de audiencia de pruebas de fojas ciento cuarenta a ciento cuarentidós, el demandante por intermedio de su apoderado judicial, reconoció que el despido se produjo por varias incidencias entre ellas al alegado permiso para regularizar su omisión al sufragio; que más aún, resulta contradictorio que el demandante alegue que se le despidió por haber solicitado dicho permiso cuando el texto de la demanda se advierte, que los permisos solicitados le fueron otorgados por su empleadora sin que ello significase problema alguno en dicho momento; consideraciones por las cuales, tampoco, es procedente amparar este extremo del petitorio de la demanda" (el subrayado es mío).

Esta resolución fue confirmada por resolución del 12.04.00, de la Sala Especializada en lo Civil Corporativizada en Procesos Abreviados y de Conocimiento. El órgano colegiado enfatizó que:

«estando a que la indemnización por daños y perjuicios por inejecución comprende el daño emergente como el lucro cesante, en cuanto sean consecuencia inmediata y directa de la ejecución, conforme lo establece el segundo párrafo del artículo mi trescientos veintiuno del Código Civil; en el presente caso no se advierte, máxime la inexistencia de relación de causalidad, el vinculo entre los hechos ocurridos y los perjuicios alegados por el demandante (sic); además de que las escalas programadas por la empresa de aviación aparecen en la revista Tráfico, conforme se aprecia de fojas cuarentidós a cuarentitrés; así como el accionante reconoce que los dolores aducidos provienen de lesiones ocurridas por el impacto de un proyectil de arma de fuego que se produjo el treintiuno de Julio de mil novecientos noventiocho, tal como fluye de fojas ciento cuarenta y uno a ciento cuarentidós; agregándose también que el demandante no ha probado que la referida Libreta Electoral se haya encontrado en las maletas que le entregaron con retraso, así como los demás daños y perjuicios aducidos" (el subrayado es mío).

Estas decisiones nos hacen recordar que quien tiene la carga de acreditar el nexo causal es el demandante, así como la no existencia o ruptura 
del mismo, al demandado. Adicionalmente, me permitiría observar que el hecho que los datos respecto de las escalas conste en una revista, no exonera de la responsabilidad por falta de información que le corresponde a la compañía de aviación respecto de sus usuarios. Sin embargo, esta omisión, tampoco sería fuente de responsabilidad civil por los malestares de salud ocurridos, ya que estos son consecuencia de un accidente sufrido anteriormente.

Como ya se señaló, el Art. $1985^{\circ}$ c.c., en materia de responsabilidad extra-contractual, recoge la teoría de la causalidad adecuada. En efecto, este numeral, al prescribir que debe existir una relación de causalidad adecuada entre el hecho y el daño producidon, está refiriéndose a la causalidad como elemento constitutivo del supuesto de responsabilidad civil (causalidad de hecho).

¿Se puede proponer una interpretación sistemática de los arts. $1321^{\circ} \mathrm{y}$ $1985^{\circ}$ c.c.? Creo que sí: el Art. $1321^{\circ}$ c.c. se refiere al quantum indemnizatorio (causalidad jurídica), mientras que el Art. $1985^{\circ}$ c.c. a la causalidad como elemento constitutivo del supuesto de responsabilidad civil (causalidad de hecho). Como lógica consecuencia, no habría inconveniente para emplear la teoría de la causalidad adecuada (como elemento constitutivo de la responsabilidad civil), incluso, en la responsabilidad por inejecución de las obligaciones. En mi opinión, no es correcta la fórmula que obliga al operador jurídico a emplear una teoría determinada de causalidad, sino el modelo legislativo adoptado por el código civil debería limitarse a prescribir que el demandante tiene la carga de acreditar el nexo causal (en ambos tipos de responsabilidad) y como consecuencia de ello, este utilizará la teoría más idónea al caso en particular. Curiosamente, las diferencias entre las mismas, no resultan ser tan antagónicas. Así, si bien se afirma que la interrupción del nexo causal reduce las distancias entre la teoría de la equivalencia y la de la causalidad adecuada ${ }^{60}$ lo mismo sucedería con la teoría de la causalidad adecuada y la de la causa próxima. Incluso, no se debe olvidar el principio básico de reintegración del patrimonio en beneficio del dañado y, de ello se deriva, que el enunciado del Art. $1321^{\circ}$ c.c. no debe ser entendido como taxativo (en cuanto al límite del resarcimiento), sino de tipo descriptivo. De otra manera, se mantendría una injustificada disparidad de tratamiento frente a lo prescrito en el Art. $1985^{\circ}$ c. c. En esta posición, se encuentra quien sostiene

60 Salvi, op. cit., p. 174. 
que «si bien el Art. $1321^{\circ}$ segundo párrafo, parece adherirse a la teoría de la causa próxima por la referencia a "consecuencia inmediata", ésta debe entenderse como la que ocurre de acuerdo al orden normal de los acontecimientos, lo que nos aleja de la literalidad del término «inmediato» y así de la concepción de "causa próxima», facilitando este razonamiento una interpretación sistemática y teleológica de las normas del Código Civil, asumiéndose en general la "tesis de la causalidad adecuada». ${ }^{61}$

Un ejemplo de análisis causal lo tenemos en un caso que se presentó entre la empresa de Servicio de Agua Potable y Alcantarillado de Lima (SEDAPAL) y Telefónica del Perú. En efecto, la última demandó a la primera por los daños ocurridos el 16.03.96, ascendientes a la suma de catorce mil quinientos cincuenta y ocho nuevos soles y noventiocho centavos, por una inundación de agua como consecuencia de la rotura de tuberías de agua potable a cargo de la demandada, originando la inundación de una cámara subterránea de cables telefónicos, ocasionando el corte del servicio en la zona. El Trigésimo Octavo Juzgado Civil, con resolución diecisiete, del 17.07.98, declaró infundada la demanda por lo siguiente:

"que, como aparece de la demanda incoada la única prueba ofrecida y actuada por el demandante con la cual se pretende acreditar la existencia del evento es la copia certificada corriente en fojas siete consistente en la constatación Policial, donde aparece que se verificó daños en una cámara de empalmar líneas telefónicas, según el acto ocasionado por la inundación de agua a consecuencia de la tubería de agua; [...] Que, la prueba antedicha es insuficiente para determinar o acreditar la existencia del hecho presuntamente dañoso, y menos con el mismo se puede acreditar que la rotura de la tubería se haya ocasionado o producido por culpa (o dolo) del demandado, y en todos los casos tampoco se ha probado la relación de causalidad prevista en el numeral mil novecientos ochenta y cinco del Código sustantivo conforme al cual debe existir una relación de causa a efecto entre el hecho y el daño producido" (el subrayado es mío).

Esta decisión fue confirmada por la Tercera Sala Civil de la Corte Superior de Justicia de Lima, con resolución del 24.12.98, enfatizando que:

61 Woolcott Oyague, La Responsabilidad Civil de los Profesionales, ARA, Lima, 2002, p. 553. 
«en el presente caso, si bien con la certificación de fojas siete se acredita la inundación de agua en el lugar que se precisa en dicho documento, empero el dictamen pericial de fojas noventa y nueve es convincente cuando concluye que no existen pruebas objetivas ni documentos técnicos que demuestren la fecha en que ocurrió el evento dañoso, las causas que lo ocasionaron, la magnitud de los perjuicios y el responsable de los mismos. La certificación policial de fojas siete es insuficiente para tales efectos".

Merece observarse con mayor detenimiento la decisión en la que se establece que no hay relación de causalidad entre el hecho que un exempleador envíe cartas a otros centros de trabajo informando que un exempleado ha sido despedido por pérdida de confianza y los daños que pueda sufrir. Así, la resolución veintidós del Tercer Juzgado Civil de Chimbote, con fecha 24.11.99, que precisa que:

"el hecho que la demandante haya cursado las cartas que corren de folio treintitrés a treinta y seis, comunicando a la AFP UNION, entre otras entidades, en la cual da cuenta que el demandante y otros han sido despedidos por pérdida de confianza; por si solas no acredita que exista una relación de causa-efecto que genere un daño económico ni moral en la persona del demandante y su familia; puesto que, siempre en un despido encierra una pérdida de confianza entre el empleador y el trabajador; máxime si como está probado se ha encontrado irregularidades al desempeño de la función como trabajador del demandado Banco; y además, el que ingrese o no a laborar en otro centro de trabajo depende directamente de la decisión del empleador en donde se pretende laborar; y una carta de esta naturaleza no le impide ni le obliga a ningún empleador a que no contrate los servicios de una persona; esta situación queda dentro de su esfera de su decisión" (el subrayado es mío).

Esta decisión fue confirmada por la resolución veintinueve de la Sala Civil de la Corte Superior del Santa, del 16.05.00. 


\section{Conclusiones}

1. En materia de responsabilidad civil, el Código Civil italiano de 1942 y el Código Civil peruano de 1984 tienen raíces comunes en el Code y en el Proyecto Franco-Italiano de 1927. No obstante ello, hay figuras que han sido asimiladas directamente por el Código Civil peruano de su homólogo italiano: tal es el caso de la responsabilidad por actividades riesgosas y la responsabilidad profesional, entre otras.

2. El análisis de imputabilidad es previo al del factor de atribución y, obviamente, distinto del juicio de culpabilidad. Por consiguiente, el privado de discernimiento, al no ser civilmente imputable, no podrá ser considerado responsable ni subjetiva, ni objetivamente.

3. De la conclusión anterior, no se debe desprender que el dañado asuma los costos del daño ocasionado, ya que este tiene puede dirigirse en contra de su representante legal, el cual tiene responsabilidad objetiva ex Art. $1976^{\circ} \mathrm{c} . c$.

4. Solo en el caso que, en la situación anterior, el representante legal no tenga manera de poder resarcir el daño, el juez podrá ordenar un resarcimiento a cargo del patrimonio del incapaz sin discernimiento, no porque este sea «responsable», sino en aplicación del factor de atribución objetivo denominado "equidad", ex Art. $1977^{\circ}$ c.c.

5. La responsabilidad solidaria objetiva de los representantes legales de los (denominados) incapaces de ejercicio con discernimiento debe excluirse en el caso de los pródigos, malos gestores y los que sufren pena que lleva anexa la inhabilitación civil.

6. En materia de responsabilidad civil por incumplimiento de las obligaciones, el segundo párrafo in fine del Art. $1321^{\circ}$ c.c., al precisar que se generará el resarcimiento por inejecución de la obligación, en cuanto los daños "sean consecuencia inmediata y directa de tal inejecución", se refiere a la causalidad jurídica, entendida como aquella que delimita la magnitud de la responsabilidad del dañante, el cual, incluso, no debe ser entendido de manera literal, sino interpretado bajo el principio de reparación integral de la víctima.

7. En materia de responsabilidad extracontractual, el Art. $1985^{\circ}$ c.c., al establecer que se generará la indemnización «debiendo existir una relación de causalidad adecuada entre el hecho y el daño producido", se refiere a la causalidad de hecho, entendida como uno de los elementos constitutivo del supuesto de responsabilidad civil, el cual determina la relación entre el hecho y el daño. 
8. De tal manera, se puede realizar una interpretación sistemática del nexo causal en la responsabilidad contractual y extracontractual diseñada en los arts. $1321^{\circ}$ y $1985^{\circ}$ c.c., al poder aplicar, en ambos la causalidad adecuada, como elemento constitutivo del supuesto de responsabilidad civil.

9. Sin embargo, se cree conveniente que en una eventual reforma legislativa, solo se debería regular que el demandante de la pretensión resarcitoria tenga la carga de acreditar el nexo causal, sin asumir ninguna teoría causal. Por cuanto la realidad supera las previsiones del legislador.

No he pretendido con esta exposición sostener que se solucionarían estos problemas interpretativos con un nuevo Código o con una ley que modifique al mismo. Estoy plenamente convencido que la labor que se impone hoy en día es la consolidación de criterios jurisprudenciales que interpreten adecuadamente nuestro ahora «mayor de edad" Código Civil. Creo que esta es la principal experiencia que podemos rescatar del sexagenario Codice.

\section{Pasaje}

Marguerite Yourcenar, Memorias de Adriano, traducido por Julio Cortázar, Editorial Sudamericana, vigésima séptima edición especial, Buenos Aires, 1999, 117-118.

"Tengo que confesar que creo poco en las leyes. Si son demasiado duras, se las transgrede con razón. Si son demasiado complicadas, el ingenio humano encuentra fácilmente el modo de deslizarse entre las mallas de esa red tan frágil. El respeto a las leyes antiguas que corresponde a lo que la piedad humana tiene de más hondo; también sirve de almohada a la inercia de los jueces. [...]. Los filósofos griegos nos han enseñado a conocer algo mejor la naturaleza humana; desde hace varias generaciones, nuestros mejores juristas trabajan en pro del sentido común".

Sea cual fuere el método interpretación que se adopte, el operador jurídico debe emplear tanto su sentido de justicia como el sentido común, sin dejar de tener en cuenta el impacto social y económico de sus decisiones. 